\title{
Estudo hidrogeológico da Formação Serra Geral na região sudoeste do estado do Paraná
}

\author{
Hydrogeological study on the Serra Geral Formation in southwestern Paraná State \\ FABIO MANASSES*, ERNANI FRANCISCO DA ROSA FILHO*, EDUARDO CHEMAS HINDI*, ANDRÉ VIRMOND LIMA \\ BITTENCOURT* \\ * Universidade Federal do Paraná \\ fabman@ufpr.br
}

\begin{abstract}
Resumo
A área de estudo localiza-se na região sudoeste do estado do Paraná com área de aproximadamente $8.675 \mathrm{Km}^{2}$. Na região ocorrem basaltos e andesitos da Formação Serra Geral. Os objetivos deste trabalho são de caracterizar a hidroquímica da água subterrânea e classificar as amostras pelos íons principais para a área de estudo. A classe dominante, segundo a classificação de Piper, são águas bicarbonatadas cálcicas. Neste trabalho foram utilizados dados de físico-químicos de 57 poços completados na Formação Serra Geral. Os parâmetros analisados foram $\mathrm{HCO}_{3-}, \mathrm{CO}_{3}{ }^{2-}, \mathrm{Cl}^{-}, \mathrm{SO}_{4}{ }^{2-}, \mathrm{Ca}^{2+}, \mathrm{Mg}^{2+}, \mathrm{Na}^{+}, \mathrm{K}^{+}$, condutividade elétrica, sílica dissolvida, dureza, nitrato, ferro total, fluoreto, temperatura, sólidos dissolvidos totais (STD) e pH. Também foram plotadas 25 amostras de rocha e as 57 amostras de água em um diagrama ternário expresso em concentrações relativas (meq/L) de cátions $\left(\mathrm{Ca}^{2+}, \mathrm{Mg}^{2+}, \mathrm{Na}^{+}, \mathrm{K}\right)$. $\mathrm{As}$ amostras também foram plotadas nos diagramas de Khorzinskii para os seguintes parâmetros: $\mathrm{Na}+$; $\mathrm{Ca} 2+; \mathrm{K}+\mathrm{e} \mathrm{H} 2 \mathrm{SiO} 4, . \mathrm{Os}$ resultados mostraram que pH varia de 6,69 a 9,95. A média do DBI utilizado foi de 3,17\%. O STD varia de 423 a $52 \mathrm{mg} / \mathrm{L}$. A concentração de fluoreto varia de 0,01 a 2,95 mg/L. O diagrama ternário com amostras de água e rochas da região de estudo indicou que as amostras de rocha têm, de um modo geral, valores mais elevados do íon magnésio e valores mais baixos dos íons cálcio, sódio e potássio. Os índices de saturação das amostras configuram valores próximos ao equilíbrio da calcita, quartzo, dolomita, calcedônia e aragonita.
\end{abstract}

Palavras-chave: Chave: hidroquímica; basalto; sistema aqüifero Serra Geral

\begin{abstract}
The study area is localized in the southwestern in Parana state with area just about $8.675 \mathrm{~km}^{2}$. In the area outcrop the basalts and andesites from Serra Geral Formation. The purpose of the study were hydrochemistry characterization and classified by majors ions in the study area. The typical waters, are bicarbonate calcium in Piper's classification. In this work are used 57 analyses physicalchemistry located in the Serra Geral Formation. The analised parameters were: $\mathrm{HCO}_{3}{ }^{-}, \mathrm{CO}_{3}{ }^{2-}, \mathrm{Cl}^{-}, \mathrm{SO}_{4}{ }^{2-}, \mathrm{Ca}^{2+}, \mathrm{Mg}^{2+}, \mathrm{Na}^{+}, \mathrm{K}^{+}$electrical conductivity, silica dissolved, nitrate, iron, fluoride, hardness, total solids, temperature and $\mathrm{pH}$. Also were used 25 datas of rock analyses and the same 57 datas of groundwater analyses in a ternary diagram expressed in concentrations (meq/L) to this parameters; $\mathrm{Ca}^{2+}, \mathrm{Mg}^{2+}, \mathrm{Na}^{+}$, and $\mathrm{K}^{+}$. These rocks is composed by augite pyroxene, as well as plagioclase. These data also analyzed in Khorzinskii diagram for parameters were $\mathrm{Na}^{+} ; \mathrm{Ca}^{2+} ; \mathrm{K}^{+}$e $\mathrm{H}_{2} \mathrm{SiO}_{4}$. The results indicate that $\mathrm{pH}$ is ranging from 6,69 to 9,95. The avereging DBI observed is 3,17\%. The STD is ranging from 423 to $52 \mathrm{mg} / \mathrm{L}$. The fluoride concentration is ranging from 0,01 to 2,95 $\mathrm{mg} / \mathrm{L}$. The ternary diagram for water and rocks samples in study area indicated that rocks, generally, higher values of magnesium and lower values of calcium, sodium and potassium. The results obtained show saturation index in equilibrium for calcite, quartz, dolomite, chalcedony and aragonita.
\end{abstract}

Keywords: hydrochemistry; basalt waters; Serra Geral aquifer System

\section{Introdução}

De acordo a SUDERHSA (Superintendência de Desenvolvimento de Recursos Hídricos e Saneamento Ambiental), cerca de $16 \%$ do abastecimento de água do estado é feito por meio de captação de aqüíferos. Em algumas cidades do interior do Estado do Paraná, esse tipo de manancial é responsável pela maior parcela de água fornecida à população como é o caso da cidade de Manfrinópolis em que $70 \%$ da água consumida é subterrânea.

A Formação Serra Geral, por ser o aqüífero mais extenso, comporta o maior número de poços perfurados até a presente data no Estado do Paraná, com cerca de $60 \%$, e 
por esta razão é a principal fonte de abastecimento de água subterrânea das cidades localizadas na região sudoeste do Estado. A água subterrânea supre as necessidades, seja no atendimento total ou parcial do abastecimento público e de atividades como irrigação, dessedentação de animais, indústria, postos de serviço, condomínios, turismo, lazer, entre outros usos, por meio da captação em poços tubulares, escavados ou fontes/ nascentes.

O objetivo deste trabalho é classificar a água subterrânea pela sua composição química em função de íons predominantes, e assim, caracterizar o quimismo da água subterrânea na área de estudo.

\section{Localização da área}

A área de estudo localiza-se na região sudoeste do Estado do Paraná. Possui área aproximada de 8.675 Km2 e é limitada a norte pelo rio Iguaçu, a sul pelo Estado de Santa Catarina, a leste pelo rio Chopin e a oeste pela Argentina (Figura 1).

\section{Contexto geológico}

A Formação Serra Geral é a denominação utilizada para a seqüência de derrames de lavas basálticas que ocorre no
Terceiro Planalto Paranaense. A área de ocorrência destas rochas, em território Paranaense, corresponde a aproximadamente $109.000 \mathrm{Km} 2$ e as espessuras chegam a 1.500 m (Araújo et al., 1995).

A Formação Serra Geral é composta essencialmente de rochas ígneas vulcânicas como basaltos toleíticos e andesitos basálticos. As principais estruturas primárias são contatos interderrames (descontinuidades atectônicas de grande extensão lateral); zonas de basalto vesicular e amigdaloidal preenchidas principalmente por calcita, quartzo e zeólitas; áreas horizontes de basalto compacto, geralmente diaclasados, característicos de zonas de exclusão, além de tratos de base de derrame, raramente vesicular, com fraturas paralelas ao contato. Associados ao mesmo ciclo de vulcanismo ocorrem diques e soleiras de diabásio, faixas fraturadas subhorizontais e subverticais, com juntas e falhas, diques de arenito injetados, tufos vulcânicos, aglomerados (Silva, 2007).

O mergulho regional ocorre na direção leste/sudoeste, com cotas que chegam a 1.100 metros da borda leste e 49 metros na foz do rio Iguaçu. A espessura máxima dessa formação, no Estado do Paraná, é de 1.400 metros, e ocorre na região de Alto Piquiri (Araújo et al., 1995).

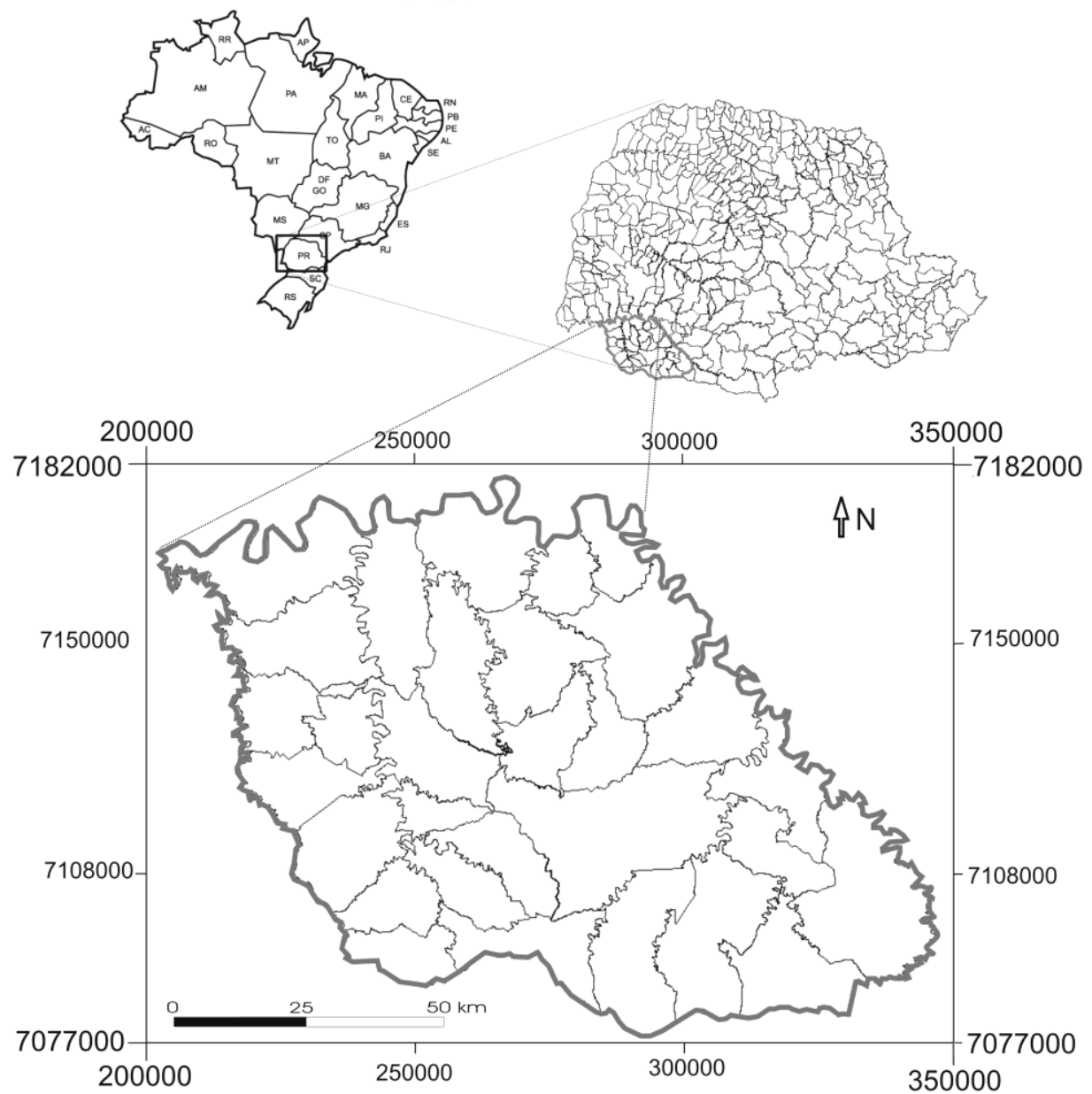

Figura 1 - Localização da área de estudo no Estado do Paraná. Coordenadas UTM (m). Datum SAD 69 - 22J. Location of the study area in Paraná State. Coordinates UTM (m). Datum SAD 69 - 22J. 
Melfi (1967, apud Gallo e Sinelli,1980) executaram uma análise modal das rochas basálticas da formação Serra Geral, resultando em plagioclásios (40 a 60\%, piroxênio (25 a $40 \%)$, magnetita e ilmenita (10\%), apatita, quartzo, feldspato potássico (0 a $2 \%$ ), clorita, biotita e anfibólios (máximo de $5 \%$ ).

No trabalho conjunto entre a MINEROPAR e a CPRM (2006), ao se interpretar imagens LANDSAT e de radar no terceiro planalto Paranaense identificaram-se três direções principais de alinhamentos estruturais (NW, NE e E-W), também referidas na literatura. Contudo, as mais proeminentes têm direção NW e, dentre estas, se destaca o alinhamento do rio Iguaçu o qual aloja espessos diques de diabásio (MINEROPAR e CPRM, 2006).

Licht (2001) identificou no sudoeste do Estado do Paraná níveis de gabro, aproximadamente horizontais, que atingem até 70 centímetros. Ocorrem encaixadas em basalto e diabásio. A rocha varia desde escura esverdeada a marrom avermelhada (devido a intemperização).

MINEROPAR e CPRM (2006), estudando a carta de Guarapuava no sudoeste do Estado do Paraná dividiram as rochas da Formação Serra Geral em estratigrafia de fácies. A interpretação de imagens LANDSAT, perfis magnetométricos regionais, levantamentos de campo, estudos petrográficos, dados de química mineral e de litoquímica convencional possibilitaram dividir o magmatismo Serra Geral da área mapeada em cinco fácies de rochas vulcânicas básicas seguintes: Fácies Nova Laranjeiras, Fácies Capanema, Fácies Campos Novos, Fácies Cordilheira Alta, Fácies Campo Erê.

A Fácies Nova Laranjareiras aflora nas cotas mais baixas da região. Os basaltos desta fácies são pretos, de aspecto geral é vítreo, de brilho resinoso e se altera para cinza acastanhado a avermelhado de aparência metálica.

A Fácies Capanema aflora nas porções mais baixas de Francisco Beltrão. Os basaltos dominantes desta fácies variam de afíricos a microfaneríticos a fracamente porfiríticos.

A Fácies Campos Novos compreende basaltos pretos, microfaneríticos a afaníticos, de aspecto microgranular fino e textura sacaróide.

A Fácies Cordilheira Alta ocorre particularmente na região de Renascença, Manfrinópolis e Pranchita a sul. Comuns nesta fácies são as intercalações de rochas sedimentares interderrames e brechas peperíticas na base dos derrames.

A Fácies Campo Erê ocorre na região sul da área de estudo, no limite com Santa Catarina. Petrograficamente, são basaltos andesíticos semelhantes aos da fácies Cordilheira Alta, da qual diferem pela ausência dos termos afaníticos e baixo índice de vesiculação.

Ferreira et al. (2008), estudando a estratigrafia dos basaltos na região de Usina Salto Segredo afirma que no basalto as estruturas variam longitudinalmente ao longo da exposição estudada do derrame. Ainda, de acordo com o autores citados acima, o perfil de apresenta três níveis: nível vesicular superior, que é marcado pela presença de grande quantidade de amígdalas e vesículas, nível maciço central, que é caracterizado por apresentar principalmente estrutura maciça, ausência de vesículas e geodos e fraturas mais regulares; nível vesicular de base, que é marcado por apresentar grande quantidade de amígdalas, porém nestas não se observa nenhum padrão de distribuição.

\section{Contexto hidrogeológico}

A Formação Serra Geral constitui-se em um aqüífero heterogêneo e anisotrópico (Rebouças, 1978) que se caracteriza por uma condutividade hidráulica muito variável, complexa e de difícil avaliação (Fraga, 1986). Rosa Filho et al. (1987) constataram que as descontinuidades físicas diminuem com a profundidade notadamente a partir de $90 \mathrm{~m}$, o que ocorre possivelmente devido a compressão dos sistemas de fraturas pela pressão resultante do maciço sobreposto.

Rosa Filho et al. (2006), afirma que a classe dominante da água do Aqüífero Serra Geral é considerada como sendo bicarbonatada cálcica conforme o diagrama de Piper. Ocorre também águas bicarbonatadas sódicas e águas bicarbonatadas cálcicas sódicas.

Uma característica importante desse aqüífero é o fato de ser constituído por rochas originalmente impermeáveis. Sob a ação da tectônica e do processo de resfriamento das rochas ígneas, criou-se uma porosidade e permeabilidade secundárias que permitem a circulação e o armazenamento de água nessas estruturas. Isto possibilitou a formação de um aqüífero Isto possibilitou a geração de um aqüífero fissurado heterogêneo e anisotrópico e portanto que, com condutividade hidráulica muito variável, complexa e de difícil avaliação (Fraga, 1986).

Rosa Filho et al. (1987) estabeleceram um zoneamento hidrogeológico para o aqüífero Serra Geral, em função das vazões dos poços analisados enquadrados aos limites das bacias hidrográficas dos rios Iguaçu, Piquiri, Paraná III, Ivaí, Pirapó, Paranapanema III, Tibagi e Cinzas. Os autores também verificaram que para profundidades maiores que $110 \mathrm{~m}$, as entradas de água são menos freqüentes. Identificaram três tipologias hidroquímicas principais: (a) águas bicarbonatadas cálcicas, típicas de basalto; (b) águas cloretadas sódicas, afins ao aqüífero Botucatu/Pirambóia (apresentando teores mais altos em sódio, pH básico e em alguns casos temperatura mais elevada); (c) águas bicarbonatadas potássicas com baixa concentração total de material solúvel relacionadas ao aqüífero Caiuá. Os autores citados, também identificaram anomalias no quimismo dessa água no que se refere aos cátions sódio, potássio, cálcio, magnésio, ao $\mathrm{pH}$ e aos sólidos totais dissolvidos.

Celligoi e Duarte (1994), em estudo de águas de poços tubulares do sistema aqüífero Serra Geral (SASG) na região de Londrina, identificaram a tipologia bicarbonatada cálcica para essas águas relacionada com a mineralogia e natureza química dessas rochas. Segundo Rosa Filho et al. (1987) as águas típicas do SASG são classificadas como bicarbonatadas cálcicas, com teores elevados de $\mathrm{Ca}++$, 
provenientes da solubilização de carbonatos, enquanto os teores de $\mathrm{Na}+$ e $\mathrm{Mg}++$ decorrem da solubilização dos feldspatos (plagioclásios) e dos piroxênios, respectivamente.

Fraga (1986) estabeleceu três fácies hidroquímicas: a fácies de águas bicarbonatadas cálcio-magnesianas e de águas bicarbonatadas cálcicas, relacionadas a natureza das estruturas armazenadoras dos derrames basálticos e a sua litoquímica, além da fácies de águas bicarbonatadas sódicas que representam mistura com águas do aqüífero Botucatu subjacente, revelando áreas de condicionamento topográfico e estrutural que permitem interconexão hidráulica entre os aqüíferos Botucatu e Serra Geral.

Buchmann (2002), ao estudar a bacia do rio Iguaçu, determinou três tipologias de água: águas bicarbonatadas cálcicas; águas bicarbonatadas sódicas; águas mistas e águas bicarbonatadas sódicas. Para este autor os dois primeiros tipos de água são mais comuns nesta bacia. Bittencourt et al. (2003) afirma que água classificadas como mista, segundo a classificação de Piper, é bastante comum no aquifero Serra Geral no Estado do Paraná.

\section{Material e métodos}

A compilação dos dados iniciou-se com a uma busca por dados de analises físico químicas de poços tubulares profundos catalogadas no banco de dados hidrogeológicos da SUDERHSA e da SANEPAR (Companhia de Saneamento do Paraná). Assim foram obtidos 650 dados de amostras com análises físico químicas. Destas, apenas 110 puderam ser usadas nesta etapa inicial de trabalho, posto que o restante não apresentava dados conclusivos. Posteriormente essas 110 amostras foram submetidas ao teste de consistência de análises, assim, restaram apenas 57 amostras. O restante das amostras não foram utilizadas porque apresentava inconsistência em seus balanços iônicos. Foram utilizados laudos de análises físico química dos poços que apresentavam os ânions $\left(\mathrm{HCO}_{3}{ }^{-}, \mathrm{CO}_{3}{ }^{2-}, \mathrm{Cl}^{-}\right.$, $\left.\mathrm{SO}_{4}{ }^{2-}\right)$ e cátions $\left(\mathrm{Ca}^{2+}, \mathrm{Mg}^{2+}, \mathrm{Na}^{+}, \mathrm{K}^{+}\right)$maiores, além de teor de $\mathrm{pH}$, condutividade elétrica, sílica dissolvida, dureza total, nitrato, ferro total, fluoreto, temperatura e sólidos dissolvidos totais (STD).

Em relação ao $\mathrm{DBI}$ foram utilizados análises físicoquímicas com valor médio de 3,17\%, tendo-se como valor máximo 8,93 \% e e mínimo de 0,02 \%. O DBI não deve ser superior a $10 \%$ para uma análise ser considerada admissível (Bittencourt \& Hindi, 2000).

Também foram obtidas 25 análises químicas de rocha cedidas pela MINEROPAR (Minerais do Paraná S.A.), as quais foram plotadas em diagrama ternário expresso em concentrações relativas (meq/L) de cátions $\left(\mathrm{Ca}^{2+}, \mathrm{Mg}^{2+}, \mathrm{Na}^{+}\right.$, $\mathrm{K}^{+}$), juntamente com as 57 amostras de água (figura 2).

Para a classificação hidroquímica foi usada a de Piper, que considera os íons plotados expressos em concentrações relativas (meq/L) de cátions $\left(\mathrm{Ca}^{2+}, \mathrm{Mg}^{2+}, \mathrm{Na}^{+}\right.$, $\left.\mathrm{K}^{+}\right)$e de ânions $\left(\mathrm{HCO}_{3}{ }^{-},+\mathrm{CO}_{3}{ }^{2-}, \mathrm{Cl}^{-}, \mathrm{SO}_{4}{ }^{2-}\right)$ em diagrama triangular (figura 3).
Os dados de análises físico-químicas das amostras de água (anexo II) que apresentaram dados de temperatura foram lançados no programa Pheereqc 2.15.02697. Assim, obteve-se como resultados os dados de molalidade, atividade iônica, além dos índices de saturação dos minerais para cada amostra. Foram plotadas um total de 15 amostras com os seguintes parâmetros $\mathrm{Ca}^{2+}, \mathrm{Mg}^{2+}, \mathrm{Na}^{+}, \mathrm{K}^{+}$, $\mathrm{HCO}_{3}{ }^{-},+\mathrm{CO}_{3}{ }^{2-}, \mathrm{Cl}^{-}, \mathrm{SO}_{4}{ }^{2-}, \mathrm{pH}, \mathrm{STD}, \mathrm{NO}^{3-}$, sílica dissolvida, Fe e temperatura. Com os resultados de atividade dos íons $\mathrm{Na}^{+}$, $\mathrm{Ca}^{2+}, \mathrm{K}^{+}$e $\mathrm{H}_{2} \mathrm{SiO}_{4}$, as 15 amostras foram plotadas, por sua vez, nos diagramas de Khorzinskii para os mesmos parâmetros.

\section{Resultados e discussão}

A concentração relativa dos íons hidrogênio na água indica se essa tem caráter ácido ou alcalino. Para a região de estudo o valor médio para $\mathrm{pH}$ é de 8,11 , o valor máximo de 9,95 e o mínimo de 6,69.

Para a condutividade registrou-se uma média de 191,24 $\mu \mathrm{S} / \mathrm{cm}$. O valor máximo obtido foi de $757 \mu \mathrm{S} / \mathrm{cm}$ e o mínimo de $80 \mu \mathrm{S} / \mathrm{cm}$.

Os teores de sólidos totais dissolvidos possuem relação direta com a composição mineralógica da rochareservatório e também com o tempo de percolação/residência das águas subterrâneas no interior do sistema. O valor médio observado foi de $147,0 \mathrm{mg} . \mathrm{L}^{-1}$, já o máximo foi de $423 \mathrm{mg} \cdot \mathrm{L}^{-1}$ e o mínimo de $52,0 \mathrm{mg} \cdot \mathrm{L}^{-1}$. Para a sílica dissolvida obteve-se uma média de $39,5 \mathrm{mg} . \mathrm{L}^{-1}$, enquanto o valor máximo obtido foi de $73,30 \mathrm{mg} \cdot \mathrm{L}^{-1}$ e o mínimo de $12,59 \mathrm{mg} \cdot \mathrm{L}^{-1}$.

No caso do nitrato o valor médio foi de $2,28 \mathrm{mg} \cdot \mathrm{L}^{-1}$ e um valor para a mediana de $1,21 \mathrm{mg} \cdot \mathrm{L}^{-1}$, ao passo que $\mathrm{o}$ máximo verificado foi de $12,91 \mathrm{mg} \cdot \mathrm{L}^{-1}$. Rosa Filho et al.,(2006) afirmam que a média para o aqüífero Serra Geral é de 4,10 mg. $\mathrm{L}^{-1}$ e o máximo de $98,3 \mathrm{mg} \cdot \mathrm{L}^{-1}$.

O valor médio de ferro total observado foi de $0,09 \mathrm{mg} . \mathrm{L}^{-}$ 1 , o valor da mediana foi de $0,05 \mathrm{mg} \cdot \mathrm{L}^{-1}$ e o valor máximo registrado foi de $0,64 \mathrm{mg} \cdot \mathrm{L}^{-1}$. O teor médio de sulfato é de $6,11 \mathrm{mg} \cdot \mathrm{L}^{-1}$, enquanto que o máximo está em a $252 \mathrm{mg} \cdot \mathrm{L}^{-1}$.

Obteve-se uma média de fluoreto de $0,22 \mathrm{mg} \cdot \mathrm{L}^{-1}$., seu teor máximo verificado é de $2,95 \mathrm{mg} . \mathrm{L}^{-1}$ e o mínimo é de $0,01 \mathrm{mg} \cdot \mathrm{L}^{-1}$. Rosa Filho et al. (2006), afirmam que o teor médio de bicarbonato da água dos poços do aqüífero Serra Geral é de 38 mg. L $^{-1}$ enquanto Fraga (1986) observou que os teores médio de bicarbonato para a unidade Iguaçu é de 69,4 mg. $\mathrm{L}^{-1}$.

Verificou-se que o teor médio de bicarbonato é de 90,3 $\mathrm{mg} \cdot \mathrm{L}^{-1}$. O máximo teor é de $221,82 \mathrm{mg} \cdot \mathrm{L}^{-1}$, o mínimo de $0,50 \mathrm{mg} \cdot \mathrm{L}^{-1}$ e o médio de $10,33 \mathrm{mg} \cdot \mathrm{L}^{-1}$. Enquanto que o valor máximo para o carbonato obtido foi de $112,0 \mathrm{mg} \cdot \mathrm{L}^{-1}$.

$\mathrm{Na}$ área de estudo verificou-se que o teor médio de sódio é de $22,71 \mathrm{mg} \cdot \mathrm{L}^{-1}$ enquanto o máximo foi de 134 mg. $\mathrm{L}^{-1}$. Fraga (1986), define os valores médios de 16,19 $\mathrm{mg} . \mathrm{L}^{-1}$ para os basaltos da bacia do rio Iguaçu. Rosa Filho et al. (2006), afirma que a média do teor de potássio do aqüífero Serra Geral corresponde a $0,87 \mathrm{mg} \cdot \mathrm{L}^{-1}$. Para este 
estudo obteve-se um valor médio de potássio referente a $0,72 \mathrm{mg} \cdot \mathrm{L}^{-1}$. O valor máximo é igual a $1,95 \mathrm{mg} \cdot \mathrm{L}^{-1}$.

O teor médio de cálcio observado é de $13,86 \mathrm{mg} \cdot \mathrm{L}^{-1}$, o máximo de $45,46 \mathrm{mg} \cdot \mathrm{L}^{-1}$ e o mínimo igual a $0,59 \mathrm{mg} \cdot \mathrm{L}^{-1}$. A mediana é de $14,82 \mathrm{mg} \cdot \mathrm{L}^{-1}$. No caso do magnésio, o teor médio é de $4,13 \mathrm{mg} \cdot \mathrm{L}^{-1}$, o máximo obtido foi de $13,61 \mathrm{mg} \cdot \mathrm{L}^{-1}$ e mínimo de $0,02 \mathrm{mg} \cdot \mathrm{L}^{-1}$.

Das 57 amostras analisadas apenas 15 destas apresentavam o dado temperatura. A temperatura média das amostras é igual a $21,4{ }^{\circ} \mathrm{C}$ com um valor máximo observado igual a $25,0^{\circ} \mathrm{C}$ e o menor valor de $19,9^{\circ} \mathrm{C}$.

No diagrama da figura 2 observa-se que as amostras de rocha possuem, de um modo geral, valores mais elevados do íon magnésio e valores mais baixos dos íons cálcio, sódio e potássio. Também se observa que as amostras de rocha não apresentam dispersão horizontal em sentido ao $\mathrm{Na}^{+}+\mathrm{K}^{+}$, que apenas é notada nas amostras de água.

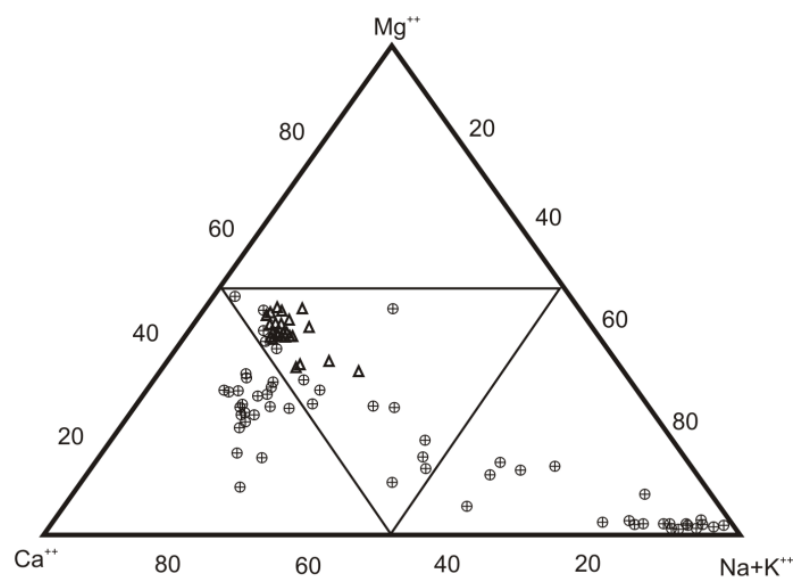

$\triangle$ Amostras de Rocha

\section{$\oplus$ Amostras de água}

Figura 2 - Diagrama ternário com amostras de rocha e água plotadas. Ternary Diagram plotted for each water and rocks samples.

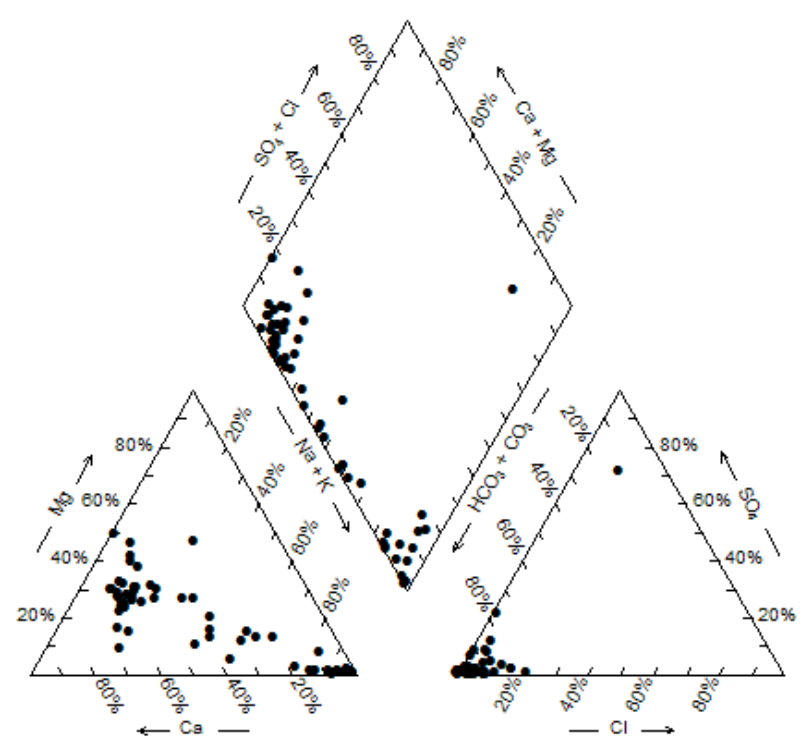

Figura 3 - Diagrama de Piper para as 57 amostras na área de estudo. Piper's Diagram for 57 water samples in study area.
No presente estudo observou-se que o predomínio das águas do SASG são as bicarbonatada sódicas $(36,8 \%)$ com 21 amostras seguida de bicarbonatada cálcica (35\%) com 20 amostras e bicarbonatadas mistas (26,3\%) com 15 amostras e por ultimo águas sulfatadas sódicas $(1,75 \%)$ com uma amostra.

No diagramas de Piper pode-se observar uma tendência de águas bicarbonatadas cálcicas e cálcio-magnesiana evoluindo para águas bicarbonatadas sódicas, retratando desta forma uma possível mistura de tipos de águas representado por águas bicarbonatadas mistas. O bicarbonato é o anion mais abundante para todas os tipos de águas, exceto para as águas sulfatadas sódicas. Nas águas bicarbonatadas mistas os cátions apresentam um equilíbrio entre si. Nas águas sulfatadas sódicas os cátions mais abundantes são o potássio junto com o sódio.

Os poços com suas respectivas classes de água apresentam-se dispersos na área de estudo (figura 4).

Os índices de saturação obtidos, indicaram equilíbrio das amostras de água com a calcita, calcedônia, aragonita e quartzo (tabela 1).

A caulinita é o argilomineral mais estável neste ambiente geoquímico conforme mostrado pelo diagrama de Khorzinskii. Esta pode ser resultante do intemperismo químico sobre as rochas na região de estudo. Os diagramas de estabilidade mineral também mostraram que as amostras ocorrem em equilíbrio com a caulinita sugere o processo de monossialitização. Isto é resultado da hidrólise parcial do plagioclásio e piroxênio em $\mathrm{pH}$ próximos a neutralidade em que o alumínio é praticamente insolúvel.

Os índices de saturação das amostras configuram supersaturação de sílica sob a forma de calcedônia e quartzo em treze amostras o que pode indicar que o piroxênio e principalmente o plagioclásio constituem as fontes de sílica.

No diagrama B (figura 5) observa-se que cinco amostras estão dispostas no campo da albita. Cinco amostras estão no campo da caulinita e cinco no campo da pirofilita. A albita é plagioclásio sódico mais comum em rochas vulcânicas como o basalto. A caulinita é um grupo de minerais de argila comum em zonas de alteração de rochas ácidas compostas de feldspatos.

No diagrama C (figura 5) observa-se que as amostras estão no campo da calcita que é um mineral comum em rochas ígneas vulcânicas alcalinas e básicas. Na Formação Serra Geral á calcita nos basaltos (Fraga, 1986).

A maioria das águas em contato com os basaltos tem uma tendência a precipitar sílica seja como quartzo, calcedônia ou outro silicato, porém a reação é mais lenta do que a intemperização da rocha primária. Estes aspectos conduzem a que sejam encontrados teores de sílica superiores aquele do equilíbrio com a forma menos cristalizada menos solúvel da sílica que é o quartzo (Bittencourt et al., 2003)

Observou-se a existência de quatro classes de água segundo Piper e são elas: águas bicarbonatadas cálcicas, 


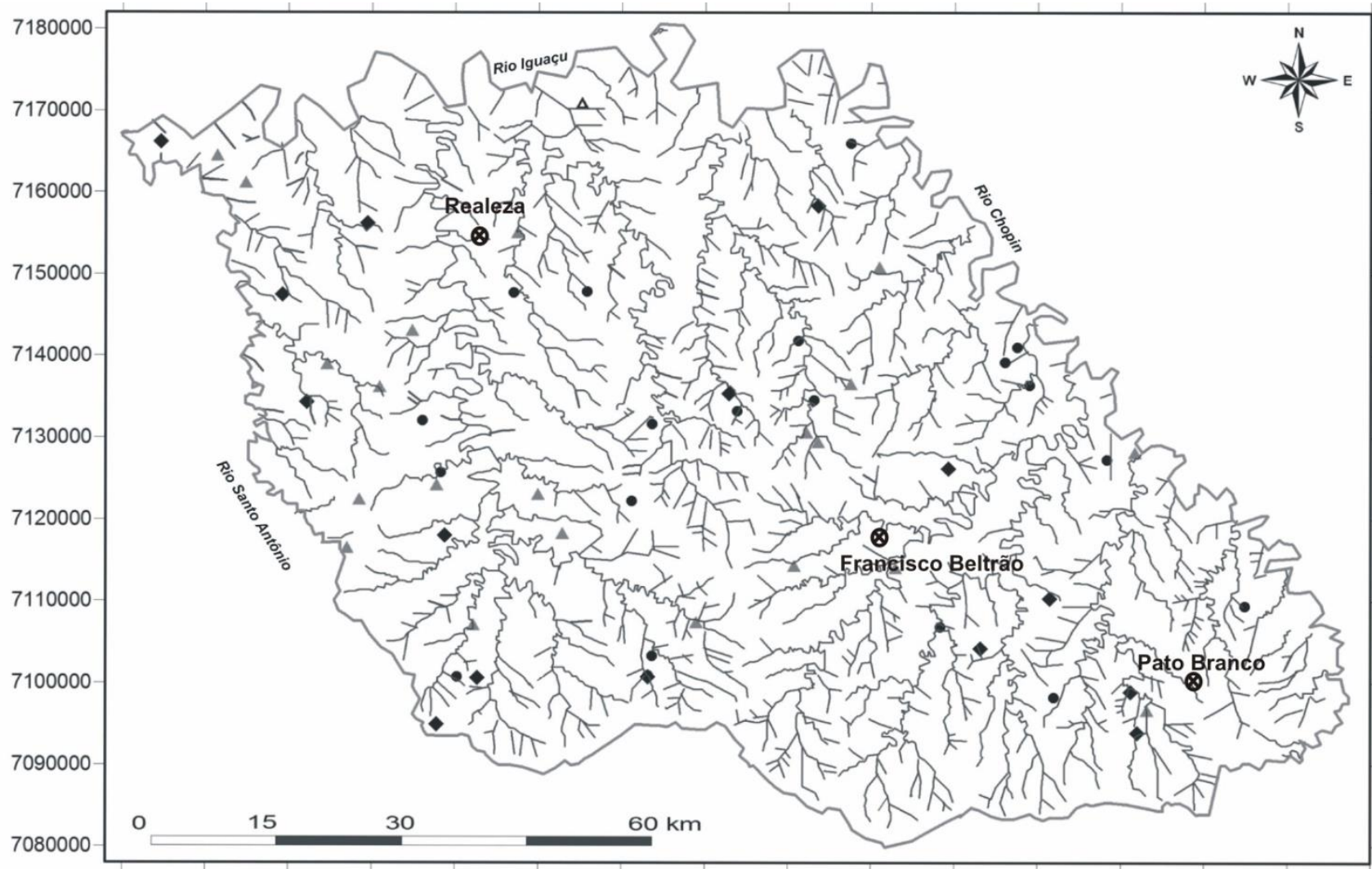

200000210000220000230000240000250000260000270000280000290000300000310000320000330000340000350000 Drenagem $\otimes$ Município $\quad \sim$ Limite da área Coordenadas UTM (m) - Datum SAD-69 22J

$\Delta$ Águas bicarbonatadas cálcicas $\bullet$ Águas bicarbonatadas mistas - Águas bicarbonatadas sódicas $\Delta$ Água sulfatada sódica

Figura 4 - Localização dos poços para cada tipo de água segundo a classificação de Piper. Water hole locate for each water sample by Piper's Classification.

Tabela 1 - Índices de saturação dos minerais para as amostras de água. Saturation index for minerals in water samples.

\begin{tabular}{l|l|l|l|l|l}
\hline & \multicolumn{5}{|c}{ ÍNDICES DE SATURAÇÃO } \\
\hline Amostra/ Mineral & CALCITA & DOLOMITA & CALCEDÔNIA & QUARTZO & ARAGONITA \\
\hline Bela Vista A & $-0,07$ & $-0,37$ & 0,64 & 1,08 & $-0,22$ \\
\hline Bom Jesus A & $-0,05$ & $-0,77$ & 0,03 & 0,47 & $-0,19$ \\
\hline Capanema A & 0,09 & $-0,04$ & $-0,34$ & 0,10 & $-0,06$ \\
\hline Capanema B & $-0,69$ & $-1,29$ & 0,51 & 0,95 & $-0,84$ \\
\hline Dois Vizinhos A & $-0,94$ & $-2,15$ & 0,36 & 0,80 & $-1,09$ \\
\hline Enéas Marques 7 & $-0,21$ & $-1,67$ & 0,16 & 0,59 & $-0,36$ \\
\hline Francisco B. 28 & $-1,19$ & $-2,54$ & $-0,08$ & 0,36 & $-1,34$ \\
\hline Manfrinópolis A & 0,47 & 0,72 & 0,68 & 1,12 & 0,33 \\
\hline Nova Esp. B & 0,43 & $-0,13$ & 0,39 & 0,83 & 0,28 \\
\hline Pérola D’Oeste A & $-0,69$ & $-1,38$ & 0,53 & 0,97 & $-0,83$ \\
\hline Realeza 1 & 0,13 & $-0,65$ & 0,02 & 0,46 & $-0,02$ \\
\hline Renascença A & $-1,23$ & $-2,80$ & 0,24 & 0,67 & $-1,37$ \\
\hline Renascença B & $-1,58$ & $-3,18$ & 0,21 & 0,65 & $-1,73$ \\
\hline Salgado Filho D & $-0,11$ & $-1,11$ & 0,41 & 0,86 & $-0,25$ \\
\hline Santo Ant. Sud. 2 & $-0,30$ & $-0,73$ & 0,50 & 0,94 & $-0,45$ \\
\hline & & & &
\end{tabular}


A

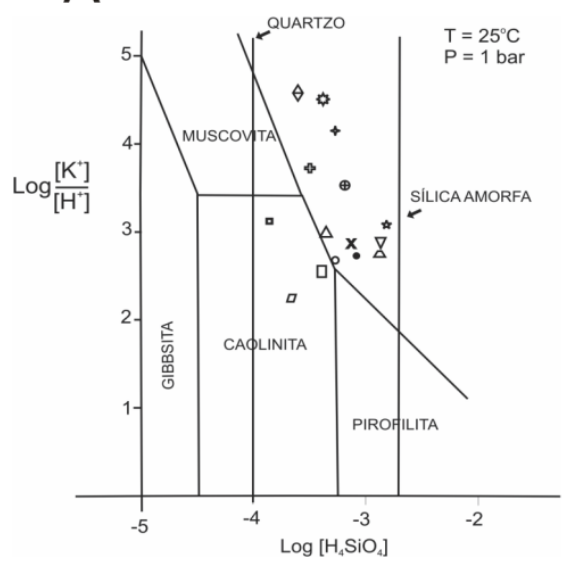

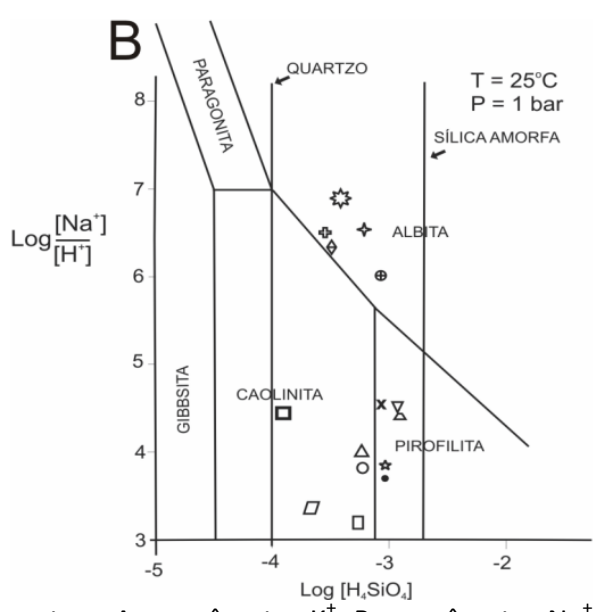

Figura 5 - Diagramas de Khorzinskii para as 15 amostras. A - parâmetro $\mathrm{K}^{+} ; \mathrm{B}$ - parâmetro $\mathrm{Na}^{+} ; \mathrm{C}$ - parâmetro $\mathrm{Ca}^{2+}$. Khorzinskii's Diagram for 15 rocks samples. A-parameter $K^{+} ; B$-parameter $\mathrm{Na}^{+} ; \mathrm{C}$-parameter $\mathrm{Ca}^{2+}$.

águas bicarbonatadas sódicas; águas bicarbonatadas mistas e águas sulfatadas sódicas. Estas classes de água ocorrem devido à interação química da água de percolação com os minerais dos basaltos da Formação Serra Geral, compostos essencialmente por plagioclásio e piroxênio que apresentam íons $\mathrm{Ca}^{2+,} \mathrm{Na}^{+}, \mathrm{Mg}^{2+}$ e $\mathrm{K}^{+}$em sua composição e estão ligados fracamente a estrutura silicatada de forma que podem passar facilmente para a água.

$\mathrm{O}$ pH observado nas amostras utilizadas varia de 6,69 a 9,95 de modo a possibilitar a ocorrência do bicarbonato em todas as amostras. Este íon pode ter sido gerado diretamente por decomposição do ácido carbônico ou como produto da hidrólise dos silicatos do basalto. Já o carbonato apresenta um valor máximo de $112 \mathrm{mg} . \mathrm{L}^{-1} \mathrm{e}$ ocorre em amostras com $\mathrm{pH}$ levemente alcalino a alcalino.

Os valores de STD variam $423 \mathrm{mg} . \mathrm{L}^{-1}$ a $52 \mathrm{mg} . \mathrm{L}^{-1}$ que pode ser reflexo de um tempo de residência potencialmente curto, que limitaria a interação água-rocha. As amostras que apresentam menores valores de STD são, de um modo geral, as de águas bicarbonatadas cálcicas, bicarbonatadas mistas e bicarbonatada magnesiana.

Águas bicarbonatadas cálcicas ocorrem em poços com entradas de água menores que $170 \mathrm{~m}$. Essas águas podem ser resultantes do intemperismo de plagioclásio cálcico e calcita. $\mathrm{O}$ caráter bicarbonático é diretamente influenciado pelo equilíbrio do sistema $\mathrm{CO}_{2}-\mathrm{H}_{2} \mathrm{O}$ vigente nas áreas próximas à recarga e também pelas reações de hidrólise dos silicatos nas rochas extrusivas. O campo das águas bicarbonatadas cálcicas possui um controle litoquímico, já que suas características químicas estão relacionadas aos processos de intemperismo que atuam sobre as rochas vulcânicas.

As águas bicarbonatadas sódicas ocorrem em poços com entradas de água predominantemente superiores a $110 \mathrm{~m}$. Estas águas estão em nítido desequilíbrio com aquilo que seria de se esperar para um aqüífero suportado por rochas basálticas típicas. São águas com quimismo provavelmente influenciado por ambiente externo ao aqüífero Serra Geral. Assim, estas águas podem evidenciar a existência de condicionadores estruturais que seriam

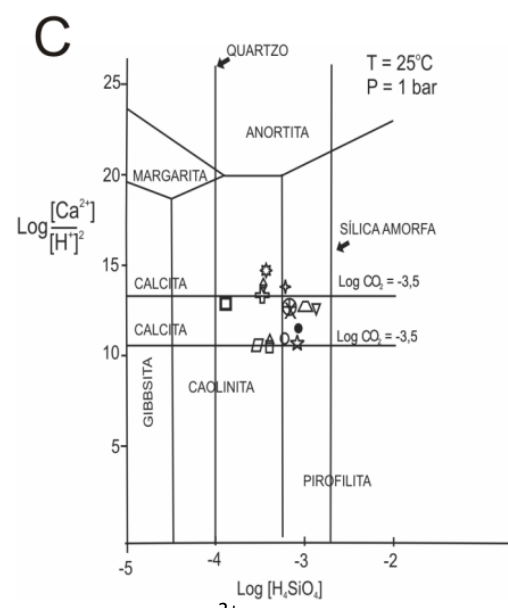

responsáveis pela mistura das águas dos aqüíferos sotopostos, principalmente o Guarani. Outra possibilidade é retratada pela depleção da quantidade de cálcio e magnésio dissolvidos, assim, o aumento dos teores relativos em sódio é uma das conseqüências que pode resultar em águas bicarbonatadas sódicas.

As águas de constituição mista ocorrem em 15 amostras na área de estudo. Composições tendendo para o pólo sódico, como já foi mencionado, sugerem contribuição de fontes infrabasálticas, enquanto que teores maiores de magnésio podem perfeitamente se relacionar apenas com os basaltos pela sua própria composição mineralógica. Esta classe de água indica uma mistura de águas bicarbonatadas cálcicas com águas bicarbonatadas sódicas.

Os basaltos, na área de estudo, são muito pobres em sulfetos e em outras formas de enxofre e isto é refletido nos baixos teores de sulfato observado. Os teores mais elevados podem sugerir misturas por águas oriundas de aqüíferos subjacentes. Assim águas sulfatadas sódicas não são comuns em basaltos da Formação Serra Geral. Uma amostra apresenta o teor de $252,20 \mathrm{mg} / \mathrm{L}$ de sulfato. A presença de pirita $\left(\mathrm{S}_{2} \mathrm{Fe}\right)$ pode elevar o teor de sulfato na água.

Os valores de cloreto, nas amostras da área de estudo, são considerados normais para o aqüífero Serra Geral. Os valores mais altos podem estar relacionados a misturas com águas de aqüíferos subjacentes, principalmente o Guarani, já que este é formado em ambiente desértico e flúvio-lacustre o que possibilitaria teores elevados de cloreto, como é o caso da amostra Nova Prata 2. Os valores de nitrato observados são considerados normais para o aqüífero Serra Geral.

O íon magnésio pode ser proveniente principalmente de ferromagnesianos do basalto.

O ferro ocorre em baixas concentrações com um máximo de 0,64 mg/L. Estes valores são compatíveis com o que é esperado para o aqüífero Serra Geral. Os valores baixos são atribuídos ao fato de que apenas parte do ferro é solubilizada, e o restante permanece nos minerais argilosos. 
Os valores de fluoreto variam de 0,01 a 2,95 mg. $\mathrm{L}^{-1}$. Os teores mais altos podem sugerir o enriquecimento em flúor em águas subterrâneas do SASG em função da interação água-rocha em prolongado tempo. Outra hipótese baseiase no controle estrutural e conexão hidráulica entre diferentes aqüíferos, por intermédio de estruturas tectônicas que possibilitam a ascensão de águas de aqüíferos sotopostos ao SASG (Nanni, 2008). Assim, o produto resultante são águas com teores acima do esperado para o fluoreto. A amostra Nova Prata A apresenta teor de $2,95 \mathrm{mg} / \mathrm{L}$ que pode ser indicativa de mistura com aqüíferos subjacentes.

Treze amostras apresentam valores esperados para este aqüífero, de $23,65{ }^{\circ} \mathrm{C}$ (Buchmann, 2002). Apenas duas amostras possuem temperatura acima de $23,65^{\circ} \mathrm{C}$.

$\mathrm{O}$ diagrama ternário indicou que as amostras de rocha têm apresentam de modo geral, valores mais elevados do íon magnésio e valores mais baixos dos íons cálcio, sódio e potássio. Verifica-se que as amostras de rocha não apresentam dispersão horizontal em sentido ao $\mathrm{Na}^{+}+\mathrm{K}^{+}$. Apenas as amostras de água apresentam dispersão em sentido ao sódio. Assim, conclui-se que uma parcela do magnésio não foi disperso na água. As amostras de água com maior teor de cálcio que as amostras de rocha indicam a facilidade da água em remover este cátion da rocha devido sua alta solubilidade. Os altos teores de sódio em amostras não ocorrem em rochas da Formação Serra Geral da região. Esta classe de água é representada pelas águas bicarbonatadas sódicas. O teor de sódio nesta classe varia de 18 a 67 mg.L $\mathrm{L}^{-1}$. Estes valores podem sugerir contribuições infrabasálticas, realçado pelo fato de amostras de rocha da região não apresentarem estes teores de sódio. O íon potássio é pouco presente nas amostras. A maior parte do potássio liberado por hidrólise é logo adsorvido por minerais argilosos. Assim as amostras de rocha apresentam-se com maior teor de sódio e potássio que as amostras de água.

A calcita é grande controladora de cálcio em águas com $\mathrm{pH}$ alcalino. $\mathrm{O}$ cálcio presente sobretudo na forma de $\mathrm{Ca}^{2+}$ é o cátion mais abundante nas amostras. Isto é o reflexo de sua facilidade de remoção de cálcio de plagioclásios do basalto.

As águas com maiores valores de $\mathrm{pH}$ são águas, geralmente, do tipo bicarbonatadas sódicas. Já as águas bicarbonatadas cálcicas e mistas apresentam os menores valores de $\mathrm{pH}$ para a área de estudo.

Os altos valores de STD podem indicar águas com maior tempo de residência. Uma amostra apresenta STD de 423 mg. $\mathrm{L}^{-1}$. Esta amostra apresenta teor de STD elevado em relação às demais amostras. Este fato corrobora para que o tempo de residência desta água seja maior, que por sua vez, possibilitou um maior tempo de interação água rocha aumentando seus teores de STD, sulfato e cloreto.

\section{Conclusão}

A classificação hidroquímica mostrou que as águas do SASG são predominantemente bicarbonatada sódicas com 21 amostras, seguida de bicarbonatada cálcica com 20 amostras e bicarbonatadas mistas com 15 amostras. Apenas uma amostra de água sulfatada sódica.

Os diagramas de Khorzinskii indicaram minerais que, por sua vez, são comuns em rochas básicas e nos seus produtos de alteração.

Os índices de saturação das amostras permitiram indicar, que de um modo geral, os minerais carbonatados apresentam tendência a precipitação, enquanto que o restante dos minerais apresentam tendência a dissolução.

O caráter bicarbonático da água é diretamente influenciado pelo equilíbrio do sistema $\mathrm{CO}_{2}-\mathrm{H}_{2} \mathrm{O}$ vigente nas áreas próximas à recarga e também pelas reações de hidrólise dos silicatos nas rochas extrusivas.

As águas bicarbonatadas sódicas são provavelmente influencia do ambiente externo ao aqüífero Serra Geral.

Águas mais ácidas são observados em amostras com STD menores. Isto indica que a acidez da solução de percolação que infiltra no solo relaciona-se com o ácido carbônico e apresenta $\mathrm{pH}$, portanto, baixo. Na medida em que a água subterrânea se move ao longo de sua linha de fluxo no aqüífero ocorre uma diminuição da acidez pelas reações de intemperismo químico e que há um aumento na quantidade de sólidos dissolvidos na solução de lixiviação. Portanto as águas com maior teor de STD, apresentam maior valor de $\mathrm{pH}$.

Entre os minerais do grupo do plagioclásio, o plagioclásio cálcico intemperiza mais rapidamente que o plagioclásio sódico, liberando cálcio e sódio na água mais rapidamente que o potássio configurando valores mais baixos de potássio na água em relação ao cálcio e sódio. Com os cátions liberados, as estruturas dos minerais são parcialmente decompostas e parcialmente reconstituídas nas estruturas dos minerais argilosos. Assim apenas uma parte do silício, sob a forma principal de ácido silícico e uma parte do alumínio são absorvidas pela solução aquosa.

\section{Referências bibliográficas}

ARAÚJO L.M., FRANÇA A.B., POTTER P.E. 1995. Aqüífero Gigante do Mercosul no Brasil, Argentina, Paraguai e Uruguai, Buena Vista, Misiones e Tacuarembó. UFPR/ Petrobrás, 16 pp.

BITTENCOUR, A.V.L., ROSA FILHO E.F., HINDI E.C., BUCHMANN FILHO A.C.A. 2003. influência dos basaltos e de misturas com águas de aqüíferos sotopostos nas águas subterrâneas do
Sistema Aqüífero Serra - Geral na bacia do Rio Piquiri, Paraná BR. Revista Águas Subterrâneas, 17, 67-75.

BUCHMANN FILHO A.C. 2002. Características das águas do Sistema Aquífero Serra Geral no Estado do Paraná. Curitiba. 150 p. Dissertação de Mestrado. Curso de Pós Graduação em Geologia, - Universidade Federal do Paraná - UFPR 
CELLIGOI, A, DUARTE U. 1994. Aspectos Hidrogeoquímicos da Formação Serra Geral em Londrina - PR - In: CONGRESSO BRASILEIRO DE ÁGUAS SUBTERRÂNEAS ., 8 Recife. Anais. Recife: ABAS. p. $425-433$

FERREIRA C.H.N., GOMES M.E.B., MESQUITA M.J.M., DUTRA C.R., BONGIOLO E.M., ARIOLI E.E. 2008. Características estruturais de um derrame e estratigrafia da região de Salto Segredo. In: IV Simpósio de Vulcanismo e Ambientes Associados, 2008, Foz do Iguaçu. Boletim de Resumos do IV Simpósio de Vulcanismo de Ambientes Associados.

FRAGA C.G. 1986. Introdução ao Zoneamento do Sistema Aquífero Serra Geral no Estado do Paraná. São Paulo, 125 p. Dissertação de Mestrado. Instituto de Geociências, Universidade de São Paulo (USP).

LICHT O.A.B. 2001.Análise multielementar na gestão ambiental Identificação e caracterização de Províncias Geoquímicas naturais, alterações antrópica da paisagem, áreas favoráveis à prospecção mineral e regiões de risco para a saúde no Estado do Paraná, Brasil. Curitiba, V1-V2. 209 f. Tese (Doutorado em Geologia) - Setor de Ciências da terra, Universidade Federal do Paraná

MELFI A.J. 1976. Potassium - Argon Ages for core sample of basaltic rocks from southern Brazil, Geoch et Cosmoch, Acta, $1079-89$

MINEROPAR \& CPRM,. GEOLOGIA E RECURSOS MINERAIS DO SUDOESTE DO ESTADO DO PARANÁ, 2006. Programa Geologia do Brasil. $101 \mathrm{p}$

NANNI A.S. 2008. O Flúor em águas do Sistema Aqüífero Serra Geral no Rio Grande do Sul: origem e condicionamento geológico./ Arthur Schmidt Nanni. - Porto Alegre: IGEO/UFRGS.

ROSA FILHO E.F. Contribuição ao Estudo das Águas Subterrâneas nos Basaltos no Estado do Paraná. Boletim Paranaense de Geociências, Curitiba, n 37, 1987, p 22-52

ROSA FILHO E.F., HINDI E.C. 2006. Diagnóstico das águas subterrâneas no Estado do Paraná: quantidade e Qualidade. Relatório Técnico.

SILVA A.B. 2007. Conectividade e Compartimentação Magnéticaestrutural dos Sistemas Aqüíferos Serra Geral e Guarani na Região Central do Estado do Paraná. Dissertação de Mestrado. Curso de Pós Graduação em Geologia, - Universidade Federal do Paraná - UFPR. 157p. 